\title{
Evaluating robustness of a diesel-degrading bacterial consortium isolated from contaminated soil
}

Sydow, Mateusz; Owsianiak, Mikolaj; Szczepaniak, Zuzanna; Framski, Grzegorz; Smets, Barth F.; awniczak, ukasz; Lisiecki, Piotr; Szulc, Alicja; Cyplik, Pawe; Chrzanowski, ukasz

\section{Published in:}

New Biotechnology

Link to article, DOI:

10.1016/j.nbt.2016.08.003

Publication date:

2016

Document Version

Peer reviewed version

Link back to DTU Orbit

Citation (APA):

Sydow, M., Owsianiak, M., Szczepaniak, Z., Framski, G., Smets, B. F., awniczak, ., Lisiecki, P., Szulc, A. Cyplik, P., \& Chrzanowski, . (2016). Evaluating robustness of a diesel-degrading bacterial consortium isolated from contaminated soil. New Biotechnology, 33(6), 852-859. https://doi.org/10.1016/j.nbt.2016.08.003

\section{General rights}

Copyright and moral rights for the publications made accessible in the public portal are retained by the authors and/or other copyright owners and it is a condition of accessing publications that users recognise and abide by the legal requirements associated with these rights.

- Users may download and print one copy of any publication from the public portal for the purpose of private study or research.

- You may not further distribute the material or use it for any profit-making activity or commercial gain

- You may freely distribute the URL identifying the publication in the public portal 


\section{Citation:}

2 Sydow, M., Owsianiak, M., Szczepaniak, Z., Framski, G., Smets, B.F., Ławniczak, Ł., Lisiecki, P., 3 Szulc, A., Cyplik, P., Chrzanowski, Ł., 2016. Evaluating robustness of a diesel-degrading 4 bacterial consortium isolated from contaminated soil. N. Biotechnol. 33, 852-859.

5 doi:http://dx.doi.org/10.1016/j.nbt.2016.08.003 
6 Evaluating structural robustness of a diesel-degrading bacterial consortium isolated from

9 Mateusz Sydow*,

10 Mikołaj Owsianiak ${ }^{\text {b }}$

11 Zuzanna Szczepaniak ${ }^{\mathrm{c}}$

12 Grzegorz Framski ${ }^{\mathrm{d}}$

13 Barth F. Smets ${ }^{\mathrm{e}}$

$14 \quad$ Łukasz Ławniczak $^{\mathrm{a}}$

15 Piotr Lisiecki ${ }^{\text {a }}$

16 Alicja Szulc ${ }^{\mathrm{a}}$

17 Paweł Cyplik ${ }^{\mathrm{f}}$

18 Lukasz Chrzanowski ${ }^{\mathrm{a}}$

${ }^{a}$ Institute of Chemical Technology and Engineering, Poznan University of Technology,

21 Berdychowo 4, 60-965 Poznań, Poland

22 b Division for Quantitative Sustainability Assessment, Department of Management Engineering,

23 Technical University of Denmark, Produktionstorvet, Building 424, DK-2800 Kgs. Lyngby,

24 Denmark

$25{ }^{\mathrm{c}}$ Institute of Food Technology of Plant Origin, Poznan University of Life Sciences, Wojska

26 Polskiego 31, 60-624 Poznań, Poland

$27{ }^{d}$ Institute of Bioorganic Chemistry, Polish Academy of Sciences, Noskowskiego 12/14, 61-704

28 Poznań, Poland

29 e Department of Environmental Engineering, Technical University of Denmark, Miljøvej, Building

30 113, DK-2800 Kgs. Lyngby, Denmark

$31 \mathrm{f}$ Department of Biotechnology and Food Microbiology, Poznan University of Life Sciences,

32 Wojska Polskiego 48, 60-627 Poznań, Poland

33

$34 *$ corresponding author

35 Tel.: + 48616653716

$36 \quad$ Fax.: + 48616653649

37 e-mail: mateusz.sydow@gmail.com (M. Sydow) 


\section{Abstract}

It is unknown whether diesel-degrading bacterial communities are structurally and functionally robust when exposed to different hydrocarbon types. Here, we exposed a diesel-degrading consortium to model either alkanes, cycloalkanes, or aromatic hydrocarbons as carbon sources to study its structural resistance. The structural resistance of the consortium was low, with changes in relative abundances of up to four orders of magnitude, depending on hydrocarbon type and bacterial taxon. The low resistance is explained by the presence of hydrocarbon-degrading specialists in the consortium and differences in the growth kinetics on individual hydrocarbons. However, despite this low resistance, the structural and functional resilience were high, as verified by re-exposing the hydrocarbon-perturbed consortium to diesel fuel. The high resilience is either due to the short exposure time, insufficient for permanent changes in consortium structure and function, or the ability of some consortium members to be maintained during exposure on degradation intermediates produced by other members. In summary, the consortium is expected to cope with short term exposures to narrow carbon feeds while maintaining its structural and functional integrity, which remains an advantage over biodegradation approaches using single species cultures.

\section{Keywords}

biodegradation, community dynamics, hydrocarbon, robustness, resilience

\section{Introduction}

Selection of microbial communities for bioaugmentation of soils contaminated with hydrocarbon mixtures, such as diesel fuel, must consider their ability to adapt to temporal changes in hydrocarbon composition over the course of biodegradation [1, 2]. Similarly, if bioremediation relies on the activity of autochthonous microorganisms, temporal changes in the community structure and function can occur [3-5]. The ability of microbial communities to resist to such, potentially irreversible, changes is one of the factors determining the success of bioremediation [6]. This ability, often referred to as robustness, is usually characterized by investigating: (i) the ability of a community to resist a change in its structure after perturbation; and (ii) the potential for recovery of the community's structure to its initial state after removal of the perturbation. These two indicators of structural robustness are referred to with the terms structural resistance and structural resilience, respectively $[7,8]$. The structure of a community may also influence its functional resilience, understood as the ability of a community to maintain a particular activity despite perturbation $[7,9,10]$.

Vila et al (2010) showed that successive biodegradation of particular hydrocarbon fractions in the marine environment is conducted by different, temporally dominant bacterial taxa [11]. Also Kostka et al. (2011) showed that Alcanivorax was the dominant taxon during linear and branched alkanes utilization in the early stages of crude oil biodegradation in marine environment, whereas Acinetobacter, Marinobacter and Pseudomonas, identified as both alkane and aromatics degraders, were the most abundant at the later stage of biodegradation [2]. Diesel-degrading consortia are similarly not thought to consists of generalist bacteria with ability for growth on all major 
hydrocarbon types (that is, linear and branched alkanes, cycloalkanes and aromatic hydrocarbons) present in a petroleum diesel fuel [1]. It is expected that the structural resistance of diesel-degrading consortia is low. If a given hydrocarbon (e.g., the branched-chain alkane pristane) is utilized by one consortium member only, the change in structure of the consortium, when exposed to that hydrocarbon, will be governed by the initial fraction of cells belonging to that consortium member, the kinetics of growth of the degrading member on that hydrocarbon, and the exposure time to the hydrocarbon. On the other hand, if a hydrocarbon can be utilized by many members of the consortium, its change in structure will depend mainly on the differences in the kinetics of growth between consortium members on that hydrocarbon. Both exposure time and the kinetics of growth are expected to play a key role in determining the structural resilience: the ability of the perturbed community to recover its initial state.

Resistance and resilience of microbial communities must be considered when constructing consortia for bioaugmentation of hydrocarbon mixtures [6]. Low resistance is undesirable if a consortium isolated on a specific hydrocarbon mixture, e.g. petroleum diesel fuel, is exposed to various hydrocarbons present in the diesel fuel over the course of biodegradation, unless the consortium is structurally and functionally resilient. Ideally, the consortium should be able to cope with narrow carbon feeds and adapt readily to varying composition of a hydrocarbon mixture over time. To date, there is limited knowledge on the structural resistance and resilience of dieseldegrading bacterial consortia associated with exposure to different hydrocarbon types.

In this paper, we use a diesel-degrading bacterial consortium to evaluate its: (i) structural resistance, measured as the degree of change in structure in terms of abundance of the dominant bacterial taxa when deprived of its typical energy source (i.e., petroleum diesel fuel) and perturbed to grow on individual model aliphatic, cycloaliphatic, or aromatic hydrocarbons; (ii) structural resilience, measured as the degree of recovery of the perturbed consortium to its initial state when re-exposed to diesel fuel after its perturbation; and (iii) functional resilience, measured as the ability of the previously perturbed and re-exposed consortium to mineralize the diesel fuel. The relative abundance of seven core taxa, used to describe the structure of the perturbed and recovered communities, was quantified using real-time PCR and the ddCt method for relative quantification [12]. In total, 6 aliphatic (n-dodecane, $n$-hexadecane, $n$-octadecane, $n$-docosane, heptamethylnonane, pristane), 5 cycloaliphatic (decalin, cycloheptane, ethylcyclohexane, butylcyclohexane, bicyclohexyl), and 8 aromatic (acenaphthene, ethylbenzene, 1,5dimethyltetraline, o-xylene, cyclohexylbenzene, naphthalene, 2-ethylnaphthalene, phenanthrene) hydrocarbons, which represent major hydrocarbon types present in petroleum diesel fuel, were employed. In addition, biodiesel (a mixture of fatty acid methyl esters) derived from rapeseed, was used. Thereby, we show how the overall low structural resistance depends on the type of hydrocarbon and bacterial taxon, and how the perturbed consortium recovers its initial state, presenting high structural and functional resilience.

\section{Materials and methods}

\subsection{Bacterial consortium}


The bacterial community employed in this study had been isolated from a soil contaminated with crude oil using selective enrichments with diesel fuel as source of carbon and energy [13]. The community contained bacteria of the following taxa: Achromobacter sp. (AchrP), Alcaligenes sp. (AlcP), Citrobacter sp. (CKK), Comamonadaceae (ComP), Sphingobacterium sp. (SphiP), Pseudomonas sp. (PseuP), and Variovorax sp. (VariP) [14]. The community has a degradation potential toward diesel and biodiesel fuels [13-16], and is able to mineralize all the individual hydrocarbons employed in this study [17].

The community was stored in $30 \%(\mathrm{v} / \mathrm{v})$ glycerol stocks at $-80^{\circ} \mathrm{C}$. To prepare an inoculum, a stock suspension ( $1 \mathrm{~mL}$ ) was transferred to a $300 \mathrm{~mL}$ Erlenmeyer flask containing $50 \mathrm{~mL}$ of mineral medium [13] and petroleum diesel fuel $(0.5 \%, \mathrm{v} / \mathrm{v})$, and was cultivated for $24 \mathrm{~h}$ at $25^{\circ} \mathrm{C}$ on an orbital shaker (120 rpm). Then, a $1 \mathrm{~mL}$ aliquot of the cell suspension was transferred to a new enrichment flask and the culture was grown for 3 days in the same conditions. This step was repeated three times and cells from the last enrichment were centrifuged at 10,000×g, washed twice with $40 \mathrm{~mL}$ of the mineral medium, re-suspended in the medium, and used as inoculum. This inoculum is further referred to as the initial community.

\subsection{Hydrocarbons}

To study the structural resistance of the community against carbon source changes, a total of 19 individual hydrocarbons representing all major hydrocarbon types present in petroleum diesel fuel, were used (Table 1). Structural resistance was also assessed against 4 model hydrocarbon mixtures and against biodiesel derived from rapeseed (Table 1). The hydrocarbons were purchased from Sigma Aldrich. The biodiesel, produced according to DIN E 51606 [18] was purchased from a supplier in Germany, whereas petroleum diesel fuel, produced according to EN 590:2004 [19] was purchased from a petrol station (PKN Orlen, Poland). Prior to experiments, all the fuels had been sterilized by filtration (Millex, pore size of $0.2 \mu \mathrm{m}$, Millipore).

\subsection{Repeated exposure to hydrocarbons}

The experimental design is presented in Figure 1. The structural resistance of the community was evaluated by comparing the relative abundances of core taxa within the initial community (that is, the preculture grown on diesel fuel) with that of the communities perturbed by the growth on individual or mixtures of defined hydrocarbons (Table 1) as sources of carbon in repeated growth experiments. First, cells (1-mL cell suspension) were transferred from the inoculum culture to 500$\mathrm{mL}$ bottles containing $50 \mathrm{~mL}$ medium and hydrocarbon or hydrocarbon mixture (including diesel fuel as initial carbon source) at concentrations given in Table 1 and cultivated at $25^{\circ} \mathrm{C}$ at $120 \mathrm{rpm}$ for 7 days. Then, aliquots were transferred to new set of bottles containing medium (the ratio of inoculum volume to total liquid volume was 1:50) and same hydrocarbons at their respective concentrations and cultivated in the same conditions for 7 days. This step was repeated 3 times, reaching 5 steps in total.

The structural resilience of the community was evaluated by comparing the structure of the initial community with that of the communities first perturbed by growth on individual hydrocarbons or defined mixtures, as described above, and then returned to grow on complex petroleum diesel fuel as sole carbon source. Again, growth on diesel was repeated by 2 sequential 
dilution passages (again, the ratio of inoculum volume to total liquid volume was 1:50), reaching 3 steps in total. Aliquots from the last growth passage were sampled to determine community structure and are referred to as recovered communities.

To assess the functional community resilience, we compared the initial and recovered communities with respect to the mineralization kinetics of petroleum diesel fuel in saturated sand microcosms.

\subsection{Structure of the community}

Real-time PCR and the ddCt method for relative quantification (12), employed earlier by Cyplik et al. (2011) [14], were used to quantify the relative abundance of the core taxa, from which we described the structure of the perturbed and recovered communities. In the ddCt methods, the relative abundance is expressed as relative quantity (RQ), where the amount of target rRNA genes for the seven bacterial taxa retrieved from the studied communities is normalized to the total number of bacterial rRNA in the respective community (Eq. 1).

$$
R Q=\frac{\left(\frac{q_{t(x)}^{T}}{q_{t(x)}^{B}}\right)}{\left(\frac{q_{t(0)}^{T}}{q_{t(0)}^{B}}\right)}=\frac{X_{N, q}}{X_{N, c b}}=(1+E)^{-\left(\Delta C_{T, q}-\Delta C_{T, c b}\right)}=(1+E)^{-\Delta \Delta C_{T}}=2^{-\Delta \Delta C_{T}}
$$

where $q^{T}{ }_{t}$ is the quantity of a taxon of interest (i.e., target in ddCt terms) in any perturbed or recovered community (i.e., sample) at time $t$ equal to 5 and 8 weeks for the perturbed and recovered communities, respectively; $q^{B}{ }_{t}$ is the quantity of total bacteria (i.e., reference) in the sample at time $t ; q^{T}{ }_{0}$ is the quantity of the target in the initial community (i.e. calibrator) at time $t$ equal to zero; $q^{B}{ }_{0}$ is the quantity of the reference in the initial community at time $t$ equal to zero. $X_{N, q}$ and $X_{N, c b}$ are thus the normalized amount of the target taxon in the sample and the normalized amount of the target taxon in the initial community, respectively. In the ddCt method, the $R Q$ is computed from the difference in threshold cycles for the target and the reference in a sample $\left(\Delta C_{T, q}\right)$ and the difference in threshold cycles for target and reference in a calibrator $\left(\Delta C_{T, c b}\right)$. The efficiency of the target $(E)$ was assumed equal to 1 [12].

Biomass was collected by centrifugation of the liquid culture at $8228 \times \mathrm{g}$ for $15 \mathrm{~min}$. Total DNA was extracted and purified using Genomic Mini kit (A\&A Biotechnology, Poland) following the manufacturer`s instruction with initial pretreatment with lysozyme $(45 \mathrm{mg} / \mathrm{mL})$, lysostaphin (200 U/mL) and mutanolysin $(250 \mathrm{U} / \mathrm{mL})$. The characteristics of primers and probe sets for the PCR can be found in Cyplik et al. (2011) [14].

\subsection{Mineralization kinetics of diesel fuel in saturated sand microcosms}

Mineralization of diesel fuel was studied in saturated sand microcosms, as described in Lisiecki et al. (2014) [20]. Briefly, $50 \mathrm{~g}$ of dry sand was placed in a sealed 1-litre glass bottles. The microcosms were spiked with diesel fuel (16 g/kg dry sand) applied on the sand surface. Then, the microcosms were inoculated with the initial community, or with the recovered community (re- 
exposed to diesel fuel after exposure to hydrocarbons) by applying a dense cell suspension ( $1 \mathrm{~mL}$; $\mathrm{OD}_{600 \mathrm{~nm}} 3 \pm 0.1$ ) on the sand surface. Afterwards, $14 \mathrm{~mL}$ of mineral medium was added to obtain full saturation. Microcosms were maintained without disturbance at $20^{\circ} \mathrm{C}$ for 28 days. The mineralization was determined by measuring $\mathrm{CO}_{2}$ content in a base trap $(10 \mathrm{~mL}$ of $0.75 \mathrm{M} \mathrm{NaOH}$ in a $20 \mathrm{~mL}$ vial) placed in microcosms. Titration of the diluted $\mathrm{NaOH}$ and $\mathrm{Na}_{2} \mathrm{CO}_{3}$ solution from the trap with $0.1 \mathrm{M} \mathrm{HCl}$ was done using an automatic titrator (Metrohm titroprocessor 686). Each experiment was carried out in triplicates.

\section{Results}

The response of the studied consortium to model hydrocarbons was hydrocarbon- and taxonspecific (Fig 2, left panel). Both increases and decreases in relative taxon abundance, up to four orders of magnitude relative to the initial community, were observed.

When exposed to $n$-alkanes, the largest changes in abundance were found for Citrobacter sp. (an increase of four orders of magnitude), and Achromobacter sp. (a decrease of three orders of magnitude) (Fig 2a). The response for other community members was somewhat smaller, within one order of magnitude. For branched-alkanes, the Alcaligenes sp., Achromobacter sp., Citrobacter sp., Comamonadaceae and Pseudomonas sp. taxa increased in relative abundance up to three orders of magnitude after exposure to heptamethylnonane and pristane (Fig 2a). On the other hand, Sphingobacterium sp. decreased in relative abundance after exposure to branched alkanes, especially pristane. No significant changes were observed for Variovorax sp. For cycloalkanes, an increase in abundance of up to two orders of magnitude (Achromobacter, Comamonadaceae and Variovorax sp.) was observed, while Citrobacter sp. and Sphingobacterium sp. did not significantly change in their abundance (Fig. 2b). For aromatic hydrocarbons, Alcaligenes sp., Comamonadaceae, Pseudomonas sp., Sphingobacterium sp. and Variovorax sp. were, in most cases, up to four orders of magnitude more abundant in comparison to their relative quantity in initial community, whereas the abundance of Achromobacter sp. and Citrobacter sp. decreased up to three orders of magnitude (Fig. 2c).

Overall, these results suggest that the structural resistance of the consortium was low. However, when these hydrocarbon-perturbed cultures were re-exposed to diesel fuel, the relative abundance of the dominant taxa returned close to the values in the initial community (Fig. 2e-h). The RQ values ( $\log _{10}$-transformed) ranged from -0.5 to 0.5 . Further, in the 28-day mineralization kinetics test, all recovered communities showed similar kinetics of diesel mineralization (Fig. 2i-l). This suggests that the ability to degrade diesel fuel, did not change, and functional resilience was high.

\section{Discussion}

\subsection{Explaining low structural resistance and high resilience}

Structural changes in the community are expected when deprived of its normal energy source, the diesel fuel, and forced to survive on a single hydrocarbon. Allison and Martiny (2008) already 
showed that the composition of microbial communities is sensitive to changes in various carbon amendments, including petroleum [21]. Although biodegradation of individual hydrocarbons was not verified in the present study, the consortium did have a potential to mineralize all the studied hydrocarbons when supplied as a mixture [17], suggesting that each individual hydrocarbon was degraded by one or more community members also when supplied as sole source of carbon and energy. This is further confirmed by an increase in turbidity that was observed in the flasks due to cell growth.

Hydrocarbon toxicity is not likely to have influenced the community structure as the consortium had been adapted to relatively high ( $>5 \mathrm{mg} / \mathrm{L}$ ) concentration of diesel fuel [13], and individual hydrocarbons were applied at subinhibitory levels. Thus, an increase of RQ values of a taxon when exposed to a specific hydrocarbon can indicate that either: (i) the hydrocarbon was a primary carbon and energy source for that taxon, or (ii) the hydrocarbon was not a primary carbon and energy source for that taxon but the taxon benefited from its biodegradation by another community member(s). On the other hand, a decrease in relative abundance could indicate that either: (i) a taxon did not have the ability to grow on the hydrocarbon and did not benefit from its biodegradation by other member(s), or (ii) the taxon degraded the hydrocarbon but its specific growth rate was smaller compared to other members of the consortium.

Allison and Martiny (2008) similarly showed that the composition of microbial communities does not recover for some time after disturbance [21]. Although we did not evaluate the functional resistance of the studied bacterial community during the study, a significant changes in mineralization of diesel fuel during stress (passages on single hydrocarbons) are expected to occur. The soil microbial community structure and functions can be both positively or negatively correlated depending on the used perturbation and measured function [22]. However, the mineralization of petroleum hydrocarbons (or hydrocarbon mixtures) seem to change with changing microbial community structure, since not all microorganisms present in the environmental communities can degrade all available carbon sources [1, 23]. Hamamura et al. (2013) already showed that mineralization of ${ }^{14} \mathrm{C}$-hexadecane was different among the same soil samples with diverse microbial community structures (induced by the contamination of soil with different hydrocarbon mixtures) [5]. In our study, despite the apparently low structural resistance, the structural and functional resilience were relatively high. This may suggest that either: (i) each identified consortium member was able to grow on each studied hydrocarbon, albeit at various rates; or (ii) not each consortium member was able to grow on each studied hydrocarbon, but the exposure time was short enough to avoid irreversible changes in community structure. The latter explanation is more likely as in diesel-degrading consortia, it is known that some bacteria degrade a wide variety of hydrocarbons (and are therefore generalists), while others are specialized to few compounds (and are therefore specialists) [1].

\subsection{Hydrocarbon-degrading specialist and generalists in the consortium}

Specialists are likely found in taxa that displayed the highest difference in relative abundance between individual hydrocarbons, such as seen for some branched-chain alkane or aromatic hydrocarbon exposures. 
Linear alkanes are generally easier to degrade as compared to the branched ones [24-27]. In our consortium, however, Sphingobacterium sp. was the only alkane-degrading taxon that had decreased RQ values when exposed to branched alkanes. By contrast, Achromobacter sp. increased in relative abundance when exposed to branched alkanes only (when exposed to $n$-alkanes a decrease in relative abundance was observed). Thus, Sphingobacterium sp. could be dominated by strains which have alkane oxidation mechanisms specific to $n$-alkanes, such as $\beta$-oxidation, whereas Achromobacter sp. could be dominated by bacteria which have alkane oxidation mechanisms specific to branched alkanes, such as $\omega$-oxidation [28]. Another example of specialized alkanedegraders could be strains within the Citrobacter sp. taxon, which increased significantly in relative abundance when exposed to $n$-alkanes or biodiesel, but less when exposed to branched alkanes and cycloalkanes, and decreased in relative abundance when exposed to all aromatic hydrocarbons. This is supported by the fact that Citrobacter sp. showed the highest increase in relative abundance among all taxa when exposed to biodiesel, which was expected as biodegradation of fatty acid methyl esters from biodiesel proceeds through the pathway known for $n$-alkanes (i.e. through fatty acid intermediates [26]). This is also in agreement with the ability of $n$-alkane degraders to grow on the $n$-alkane oxidation products [29].

Metabolic pathways of cycloalkanes are less characterized than those for linear or branched alkanes [26, 30]. During oxidation of a cyclic alkanes dicarboxylic acids are usually formed, similarly to $\omega$-oxidation of branched alkanes [28, 30]. This could explain why the species expected to be primary $n$-alkane degraders, such as Citrobacter sp. or Sphingobacterium sp. did not increase in abundance when exposed to cyclic alkanes. By contrast, based on RQ values Alcaligenes sp., Comamonadaceae are expected to be dominated by generalists with regard to their potential for degradation of alkanes, with both $\beta$-oxidation and $\omega$-oxidation mechanisms co-occurring within these taxa [31].

Apart from Achromobacter sp. and Citrobacter sp., all taxa increased in relative abundance when exposed to aromatic hydrocarbons. This is consistent with the ability of AlcP, ComP, PseuP SphiP and VariP to degrade various aromatic hydrocarbons [32-41]. Relatively large increases in abundance after exposure to aromatic hydrocarbons are associated with somewhat lower increase in abundance of the taxa when exposed to $n$-alkanes, indicating that aromatic hydrocarbons are the preferential carbon source within the studied community. However, bacteria belonging to Pseudomonas sp. and Alcaligenes sp. are known to degrade a wide variety of compounds, including alkanes (e.g. dodecade, pristine) [37, 42, 43], cycloalkanes (e.g. cyclohexane, decaline) [37, 44, 45] and aromatic hydrocarbons (e.g. benzene, phenanthrene) [35, 36, 37, 39, 40] and are thus expected to be hydrocarbon-degrading generalists.

\section{Conclusions}

We showed that a diesel-degrading bacterial consortium was structurally and functionally robust when employed for biodegradation of various hydrocarbons. The robustness of the microbial community was evaluated by investigating the structural and functional resilience and resistance. Despite low structural resistance, which was explained by the presence of hydrocarbon-degrading specialists in the consortium and differences in the kinetics of growth, the structural and functional 
resilience were high. The robustness of the diesel-degrading consortium is an advantage when employed for biodegradation (e.g. bioaugmentation) of environments which may have varying hydrocarbon composition over time. Such a consortium is expected to be able to cope with narrow carbon feeds yet maintaining structural and functional integrity, which is advantageous over biodegradation carried out by single species.

Our findings raise several additional questions. First, it is unknown whether the results are applicable to other hydrocarbon-degrading consortia isolated on complex hydrocarbon mixtures. Second, it is unknown whether the structural and functional robustness is a property of consortia isolated from contaminated environments, or whether such a (robust) consortium can be constructed from single species of known ability to degrade specific hydrocarbons. Third, the applicability of these results to field conditions needs to be examined as mass transfer limitations of carbon sources and availability of nutrients may play a large role in shaping community structure. Finally, it is unknown whether the consortium maintains its structural and functional integrity if longer exposure times are used. Biodegradation time scales in soils or aquifers are longer than a few weeks, in which case structural robustness and functional performance might be challenged.

\section{Acknowledgements}

This research was founded by the National Science Centre of Poland in the framework of DEC2013/11/D/NZ9/00100 project (grant no. 2013/11/D/NZ9/00100). Dr. Ireneusz Miesiąc (PUT) is gratefully acknowledged for supplying with the biodiesel fuel, and for providing access to analytical instruments.

\section{References}

[1] Ciric L, Philip JC, Whiteley AS. Hydrocarbon utilization within a diesel-degrading bacterial consortium. FEMS Microbiol Lett 2010;303:116-22.

[2] Kostka JE, Prakash O, Overholt WA, Green SJ, Freyer G, Canion A et al. Hydrocarbondegrading bacteria and the bacterial community response in Gulf of Mexico beach sands impacted by the deepwater horizon oil spill. Appl Environ Microb 2011;77:7962-74.

[3] Ciric L, Griffiths RI, Philp JC, Whiteley AS. Field scale molecular analysis for the monitoring of bacterial community structures during on-site diesel bioremediation. Bioresour Technol 2010;101:5235-41.

[4] Hamamura N, Olson SH, Ward DM, Inskeep WP. Microbial population dynamics associated with crude-oil biodegradation in diverse soils. Appl Environ Microbiol 2006;72:6316-24. 
[5] Hamamura N, Ward DM, Inskeep WP. Effects of petroleum mixture types on soil bacterial population dynamics associated with the biodegradation of hydrocarbons in soil environments. FEMS Microbiol Ecol 2013;85:168-78.

[6] Bell TH, Yergeau E, Juck DF, Whyte LG, Greer CW. Alteration of microbial community structure affects diesel biodegradation in an Arctic soil. FEMS Microbiol Ecol 2013;85:51-61.

[7] Little AEF, Robinson CJ, Peterson SB, Raffa KF, Handelsman J. Rules of engagement: interspecies interactions that regulate microbial communities. Annu Rev Microbiol 2008;62:375401.

[8] Antonopoulos DA, Huse SM, Morrison HG, Schmidt TM, Sogin ML, Young VB. Reproducible community dynamics of the gastrointestinal microbiota following antibiotic perturbation. Infect Immun 2009;77: 2367-75.

[9] Gentile ME, Nyman JL, Criddle CS. Correlation of patterns of denitrification instability in replicated bioreactor communities with shifts in the relative abundance and the denitrification patterns of specific populations. ISME J 2007;1:714728.

[10] Bell CW, Acosta-Martinez V, McIntyre NE, Cox S, Tissue DT, Zak JC. Linking microbial community structure and function to seasonal differences in soil moisture and temperature in a Chihuahuan Desert grassland. Microb Ecol 2009;58:827-42.

[11] Vila J, Nieto JM, Mertens J, Springael D, Grifoll M. Microbial community structure of a heavy fuel oil-degrading marine consortium: linking microbial dynamics with polycyclic aromatic hydrocarbon utilization. FEMS Microbiol Ecol 2010;73:349-62.

[12] Livak KJ, Schmittgen TD. Analysis of relative gene expression data using real-time quantitative PCR and the 2-[Delta][Delta]CT method. Methods 2001;25:402-08.

[13] Owsianiak M, Szulc A, Chrzanowski Ł, Cyplik P, Bogacki M, Olejnik-Schmidt AK et al. Biodegradation and surfactant-mediated biodegradation of diesel fuel by 218 microbial consortia are not correlated to cell surface hydrophobicity. Appl Microbiol Biotechnol 2009;84:545-53.

[14] Cyplik P, Schmidt M, Szulc A, Marecik R, Lisiecki P, Heipieper HJ et al. Relative quantitative PCR to assess bacterial community dynamics during biodegradation of diesel and biodiesel fuels under various aeration conditions. Bioresource Technol 2011;102:4347-52.

[15] Owsianiak M, Chrzanowski Ł, Szulc A, Staniewski J, Olszanowski A, Olejnik-Schmidt AK et al. Biodegradation of diesel/biodiesel blends by a consortium of hydrocarbon degraders: Effect of the type of blend and the addition of biosurfactants. Bioresource Technol 2009;100:1497-1500. 
[16] Chrzanowski Ł, Dziadas M, Ławniczak Ł, Cyplik P, Białas W, Szulc A et al. Biodegradation of rhamnolipids in liquid cultures: Effect of biosurfactant dissipation on diesel fuel/B20 blend biodegradation efficiency and bacterial community composition. Bioresource Technol 2012;111:328-35.

[17] Lisiecki P. The influence of biodiesel on biodegradation of diesel fuel. PhD dissertation. Poznan University of Technology 2013.

[18] DIN E 51606. Liquid fuels - Diesel fuel of fatty acid methylester (FAME) - Specifications, German Institute for Standardization 1997.

[19] EN 590:2004. Automotive fuels - Diesel - Requirements and test methods, European Committee for Standardization 2004.

[20] Lisiecki P, Chrzanowski Ł, Szulc A, Ławniczak Ł, Białas W, Dziadas M et al. Biodegradation of diesel/biodiesel blends in saturated sand microcosms. Fuel 2014;116:321-27.

[21] Allison SD, Martiny JBH. Resistance, resilience, and redundancy in microbial communities. P Natl Acad Sci USA 2009;105:11512-19.

[22] Riah-Anglet W, Trinsoutrot-Gattin I, Mertin-Laurent F, Laroche-Ajzenberg E, Norini M-P, Latour X, et al. Soil microbial community structure and function relationships: A heat stress experiment. Appl Soil Ecol 2015;86:121-30.

[23] Mariadassou M, Pichon S, Ebert D. Microbial ecosystems are dominated by specialist taxa. Ecol Lett 2015;18:974-82.

[24] Olson JJ, Mills GL, Herbert BE, Morris PJ. Biodegradation rates of separated diesel components. Environ Toxicol Chem 1999;18:2448-53.

[25] Rojo F. Degradation of alkanes by bacteria. Environ Microbiol 2009;11:2477-90.

[26] Rojo F. Enzymes for aerobic degradation of alkanes. In: Timmis K, editor. Handbook of hydrocarbon and lipid microbiology, Berlin. Springer Berlin Heidelberg; 2010, p. 781-97.

[27] Parales RE. Hydrocarbon degradation by Betaproteobacteria. In: Timmis K, editor. Handbook of hydrocarbon and lipid microbiology, Berlin. Springer Berlin Heidelberg; 2010, p. 1715-24.

[28] Solano-Serena F, Marchal R, Vandecasteele J-P. Biodegradation of aliphatic and alicyclic hydrocarbons, In: Vandecasteele JP, editor. Petroleum microbiology: concepts, environmental implications, industrial applications, Paris. Editions Technip; 2008, p. 186-211. 
[29] Dashti N, Al-Awadhi H, Khanafer M, Abdelghany S, Radwan D. Potential of hexadecaneutilizing soil-microorganisms for growth on hexadecanol, hexadecanal and hexadecanoic acid as sole sources of carbon and energy. Chemosphere 2008;70:475-79.

[30] Kirkwood KM, Chernik P, Foght JM, Gray MR. Aerobic biotransformation of decalin (decahydronaphthalene) by Rhodococcus spp.. Biodegradation 2008;19:785-94.

[31] Johnson RJ, West CE, Swaih AM, Folwell BD, Smith BE, Rowland SJ et al. Aerobic biotransformation of alkyl branched aromatic alkanoic naphthenic acids via two different pathways by a new isolate of Mycobacterium. Environ Microbiol 2012;14:872-82.

[32] Meyer S, Moser R, Neef A, Stahl U, Kampfer P. Differential detection of key enzymes of polyaromatic-hydrocarbon-degrading bacteria using PCR and gene probes. Microbiology 1999;145:1731-41.

[33] Jeon CO, Park W, Ghiorse WC, Madsen EL. Polaromonas naphthalenivorans sp. nov., a naphthalene-degrading bacterium from naphthalene-contaminated sediment. Int J Syst Evol Micr 2004;54, 93-97.

[34] Przybulewska K, Wieczorek A, Nowak A. Isolation of microorganisms capable of styrene degradation. Polish J of Environ Stud 2006;15:777-83.

[35] Arun A, Raja PP, Arthi R, Ananthi M, Kumar KS, Eyini M. Polycyclic aromatic hydrocarbons (pahs) biodegradation by basidiomycetes fungi, Pseudomonas isolate, and their cocultures: Comparative in vivo and in silico approach. Appl Biochem Biotechnol 2008;151: 132-42.

[36] Farhadian M, Vachelard C, Duchez D, Larroche C. In situ bioremediation of monoaromatic pollutants in groundwater: A review. Bioresource Technol 2007;99:5296-5308.

[37] Plaza GA, Lukasik K, Wypych J, Nałęcz-Jawecki G, Berry C, Brigmon RL. Biodegradation of crude oil and distillation products by biosurfactant-producing bacteria. Polish J of Environ Stud 2008;17:87-94.

[38] Weelink SAB, Tan NCG, ten Broeke H, van den Kieboom C, van Doesburg W, Langenhoff AAM et al. Isolation and characterization of Alicycliphilus denitrificans strain bc, which grows on benzene with chlorate as the electron acceptor. Appl Environ Microbiol 2008;74:6672-81.

[39] Cao B, Nagarajan K, Loh K-C. Biodegradation of aromatic compounds: current status and opportunities for biomolecular approaches. Appl Microbiol Biotechnol 2009;85:207-28. 
488 [40] Deveryshetty J, Phale PS. Biodegradation of phenanthrene by Alcaligenes sp. strain PPH: 489 partial purification and characterization of 1-hydroxy-2-naphthoic acid hydroxylase. FEMS 490 Microbiol Lett 2010;311:93-101.

491

492

493

494

495

496

497

498

499

500

501

502

503

504

505

506

507

508

509

510

511

512

513

514

515

516

517

[41] Satola B, Wübbeler JH, Steinbüchel A. Metabolic characteristics of the species Variovorax paradoxus. Appl Microbiol Biotechnol 2013;97:541-60.

[42] Yuste L, Corbello ME, Turiégano MJ, Karlson U, Puyet A, Rojo F. Characterization of bacterial strains able to grow on high molecular mass residues from crude oil processing. FEMS Microbiol Ecol 2010;32:69-75.

[43] Rocha CA, Pedregosa AM, Laborda F. Biosurfactant-mediated biodegradation of straight and methyl-branched alkanes by Pseudomonas aeruginosa ATCC 55925. AMB Express 2011;1:9.

[44] Kumar M, Leon V, De Sisto Materano A, Ilzins OA, Galindo-Castro I, Fuenmayor SL. Polycyclic aromatic hydrocarbon degradation by biosurfactant-producing Pseudomonas sp. IR1. Z Naturforsch A 2006;61c:203-12.

[45] Anderson MS, Hall RA, Griffin M. Microbial metabolism of alicyclic hydrocarbons: Cyclohexane catabolism by a pure strain of Pseudomonas sp. J Gen Microbiol 1980;120:80-94.

\section{Figure captions}

Fig. 1. Experimental design for evaluating structural resistance and resilience and functional resilience of a diesel-degrading bacterial consortium.

Fig 2. Relative quantity (RQ) values (in $\log _{10}$ scale) of hydrocarbon-perturbed cultures of the diesel-degrading bacterial consortium (a-d); of the hydrocarbon-perturbed cultures re-exposed to diesel fuel (e-h), and diesel fuel mineralization kinetics with respect to recovered communities and initial community (i-l). Error bars represent standard errors of the mean. 


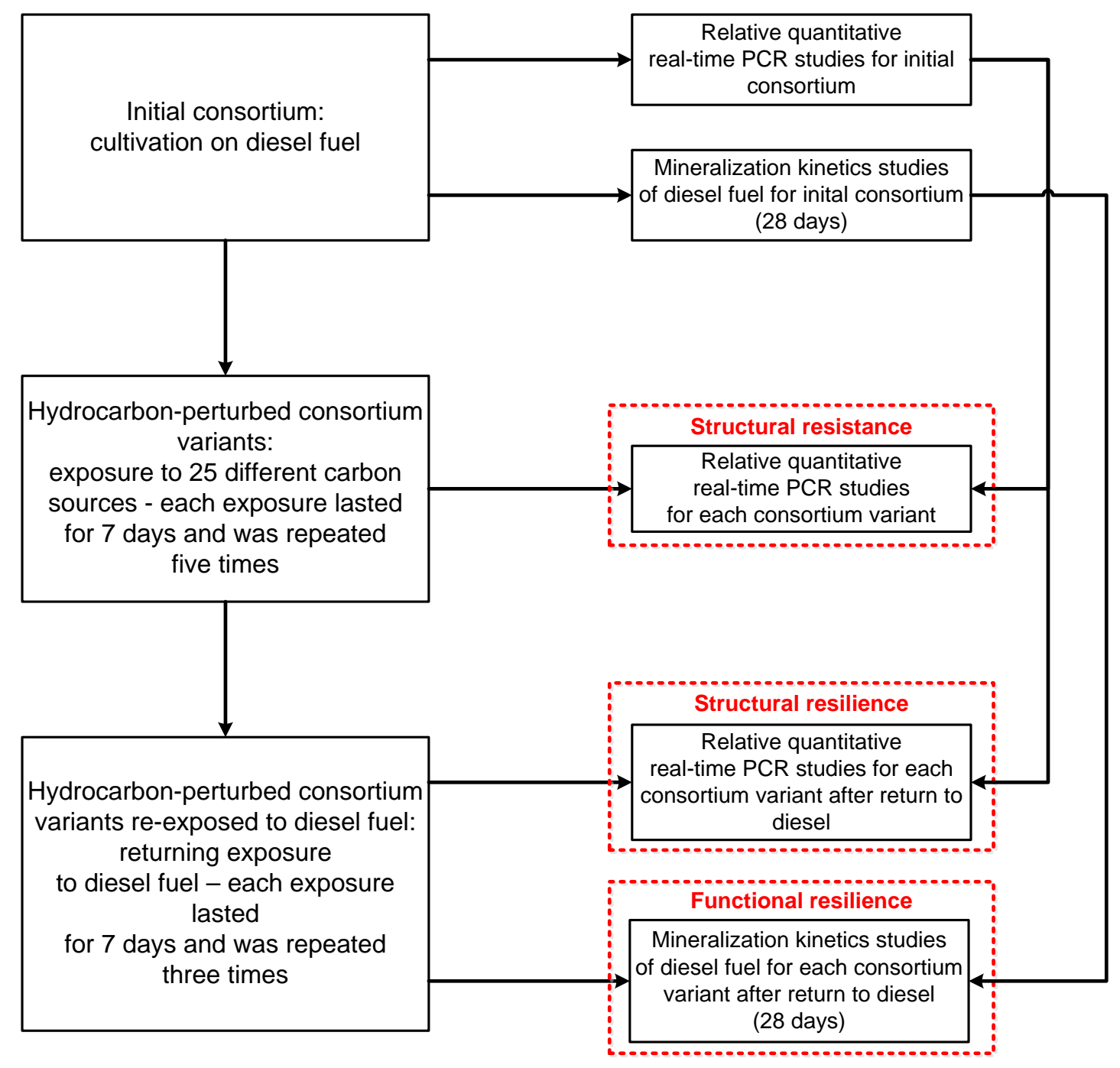

Fig. 1. 

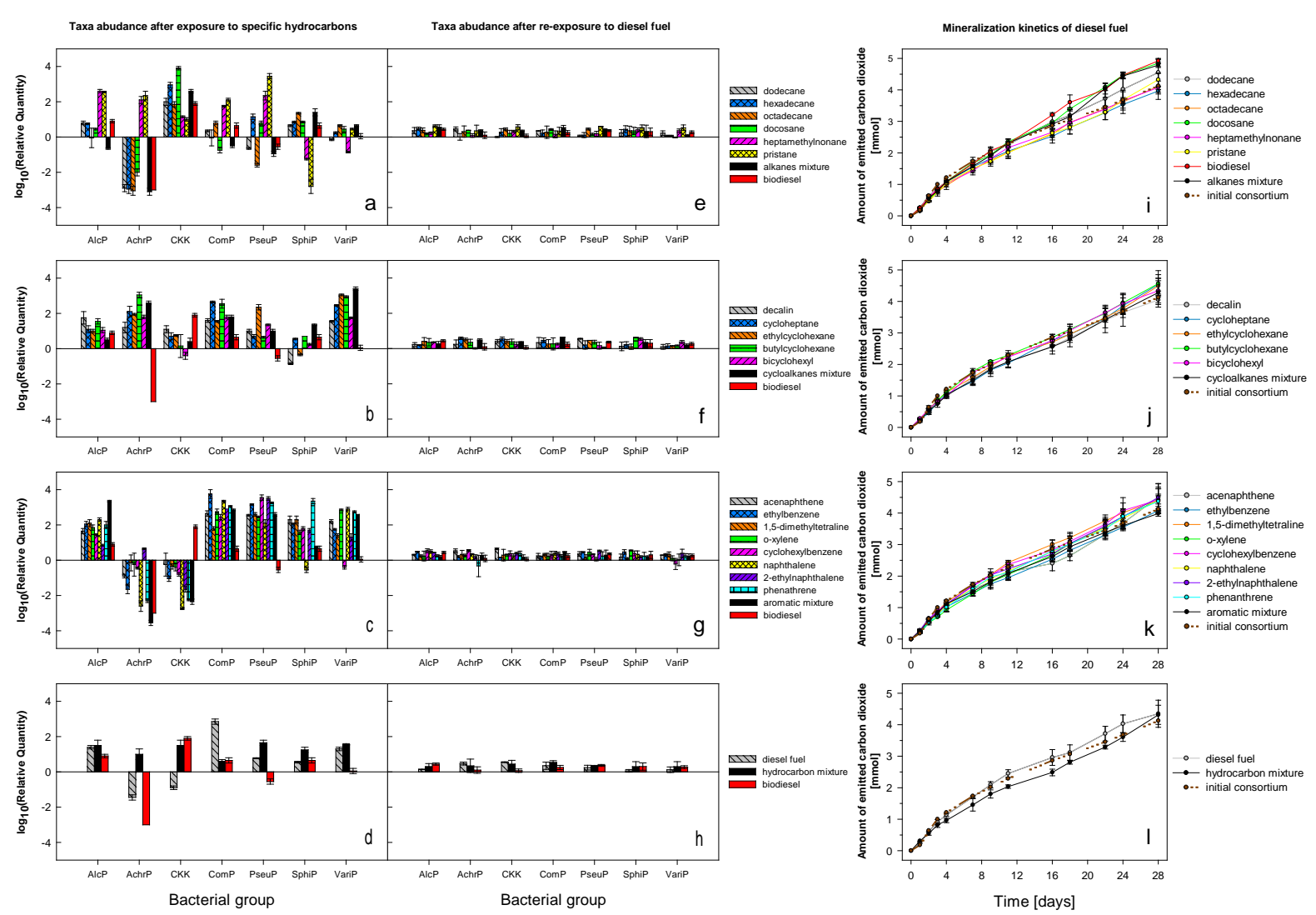

Fig. 2. 